\title{
RELEITURA DO CONCEITO DE COSMOGRAFIA: A INTERFACE ENTRE OS ESTUDOS ASTRONÔMICOS E GEOGRÁFICOS
}

Paulo Henrique Azevedo Sobreira*

Resumo: 0 conceito de "Cosmografia" está em desuso desde os anos 80 do século $\mathrm{XX}$, mas os temas astronômicos anteriormente abordados nas disciplinas escolares de Cosmografia e de Geografia permanecem nos atuais livros didáticos. O uso do termo "Cosmografia" foi resgatado nesta pesquisa e o estudo de sua ressignificação proporcionou o surgimento do termo Cosmografia Geográfica. A Cosmografia Geográfica é um campo de estudos da Geografia, cujo conjunto de conhecimentos e habilidades é predominantemente escolar. Estuda a interface entre os conhecimentos terrestres e os celestes e Ihes atribui significância geográfica. Analisa as relações humanas e naturais com o Espaço Sideral e suas consequências para a sociedade e a natureza.

Palavras-chave: Cosmografia, Cosmografia Geográfica, Ensino de Geografia, Ensino de Astronomia em Geografia.

\section{REREADING OF COSMOGRAPHY CONCEPT: THE INTERFACE BETWEEN THE ASTRONOMICAL STUDIES AND GEOGRAPHIC}

\begin{abstract}
The concept of "Cosmography" is in disuse since the 80s of the twentieth century, but the astronomical themes previously discussed in the school subjects of Geography and Cosmography remain in current textbooks. The use of term "Cosmography" was rescued in this research and the study of its resignification permited the appearance of the term Geographic Cosmography. The Geographic Cosmography is a field of studies of the Geography, whose set of knowledge and skills is predominantly school. It studies the interface between terrestrial and celestial knowledge and them assigns geographic significance. It examines human and natural relationships with Sidereal Space and its consequences for society and nature.
\end{abstract}

Key Words: Cosmography, Geographic Cosmography, Geography Teaching, Astronomy Teaching in Geography.

\section{Introdução}

O termo "Cosmografia" está em desuso desde a primeira metade do século XX e praticamente ele desapareceu durante os anos 80 e 90, após uma longa história respeitável que remonta à Antiguidade Clássica e cujo auge foi na Idade Moderna (LAMB, 1995).

As atribuições da Cosmografia foram incorporadas pela Astronomia, Cartografia, Náutica e Geografia, no entanto, sua função pedagógica de Ensino de Astronomia permaneceu ativa nas práticas dos ensinos de Matemática e de Geografia no Brasil, ao longo dos séculos XIX e XX, respectivamente, e principalmente na Geografia.

Ao longo do tempo a cosmovisão ou conceito de "Mundo" mudou, assim como o significado do termo "Cosmografia", em consequência, os objetos de estudos desse campo também. Atualmente, ela não possui o

\footnotetext{
* Graduado (Licenciatura e Bacharelado) em Geografia (1994),Mestre (2002) e Doutor (2006) em Geografia Física, pela USP. Professor Adjunto da UFG - Planetário de Goiânia e atua na graduação e no Programa de Pós-Graduação e Pesquisa em Geografia do Instituto de Estudos Socioambientais - UFG. Email: sobreiracosmografia@yahoo.com.br
} 
mesmo propósito da Cosmografia dos séculos XIX e XX, por exemplo.

No século XIX com a autonomia acadêmica da Geografia, a Cosmografia, que nunca teve características de Ciência independente, se enfraqueceu e cedeu espaço ao desenvolvimento da Cosmologia Moderna e da Cartografia, caindo parcialmente em esquecimento universitário e escolar na segunda metade do século XX.

Nas últimas décadas do século $\mathrm{XX}$ ocorreram grandes avanços nos conhecimentos das ciências celestes e terrestres e que exigiram especializações e subdivisões dessas áreas.

Deste modo, a Cosmografia necessita ser resgatada, neste século XXI, inicialmente para que os estudiosos contemporâneos e os professores de Geografia e de Astronomia compreendam a importância histórica e genealógica entre os Conhecimentos Celestes e Terrestres, e principalmente, porque os assuntos associados ao Espaço Sideral são atualíssimos.

A Cosmografia se diversificou na Era Espacial até o início do século XXI no Ensino de Geografia, se caracterizando como o Ensino de Astronomia em Geografia ou Cosmografia Geográfica (SOBREIRA, 2006).

O Espaço Sideral tornou-se o segundo lar da Humanidade, desde a década de 1960, inicialmente com as esporádicas e curtas missões espaciais soviéticas e estadunidenses, e posteriormente, pelo uso de estações espaciais para longas permanências em órbita terrestre.

Desde 1973 até a atualidade, os humanos ficam dias, meses e anos em órbita terrestre, por meio de diversos empreendimentos, tais como a estação espacial estadunidense SKYLAB; a missão conjunta APOLLO-SOYUZ em 1975; as longas viagens dos ônibus espaciais dos EUA entre
1981 e 2011; a estação espacial soviética/russa MIR e a EEI (Estação Espacial Internacional), esta última está em órbita desde 1998.

O Espaço Sideral foi apropriado pela Humanidade na Era Astronáutica e, além do mais, como consequência dos lançamentos astronáuticos, adicionou-se ao nosso vocabulário um novo termo: o lixo espacial, que é uma forma de poluição do Espaço Sideral.

O lixo espacial é um perigo constante para os lançamentos aeroespaciais de novos equipamentos e, do mesmo modo, na superfície terrestre. Anualmente se computam quedas de partes desse material e, em qualquer momento, esse lixo pode provocar acidentes ou até mesmo desencadear guerras, pois alguns tipos de detritos ao penetrar na atmosfera em alta velocidade aparecem nas telas dos radares tal como se fossem mísseis intercontinentais.

As empresas estatais e as privadas, que detêm recursos humanos e equipamentos aeroespaciais, utilizam o Espaço Sideral como área de desenvolvimento de telecomunicações, novos materiais e biotecnologias, portanto, o Espaço Sideral envolve relações humanas, sociais, políticas e econômicas e é também parte dos estudos da Geografia e deve ser ampliado e possivelmente denominado por Espaço Cósmico ou Exterior.

Para alicerçar ainda mais este raciocínio, basta tomar como exemplo as disputas travadas na corrida espacial durante os anos de Guerra Fria, a partir do lançamento do satélite soviético Sputnik I, em 1957, o processo de conquista e a exploração da Lua pelos EUA e pela ex-URSS, a atual preparação internacional para a viagem tripulada à Marte e o retorno à Lua, a competição e a cooperação internacionais 
pelo domínio das tecnologias da Terceira Revolução Industrial, da qual se destaca a indústria aeroespacial, as telecomunicações via satélite, o desenvolvimento de medicamentos e de pesquisas físicas, metalúrgicas e biotecnológicas, em geral, em ambiente de microgravidade, além do uso do Espaço Sideral ou Universal/Exterior como área de espionagem militar e monitoramento de recursos naturais da Terra e de outros astros do Sistema Solar. Até o momento, há quase uma dezena de satélites de Sensoriamento Remoto e coleta de dados em torno da Lua e de Marte.

Em 4 de julho de 2005, a sonda "Deep Impact" colidiu com o cometa Tempel 1 para possibilitar diversos estudos sobre 0 núcleo de um cometa e, por outro lado, assegurar que há recursos tecnológicos para interceptar um cometa ou asteróide que esteja em trajetória de colisão com a Terra.

\section{O Espaço Sideral também foi} alcançado pela iniciativa privada. A "Spaceshipone" tornou-se a primeira nave espacial particular, com três tripulantes, a atingir 100 km de altitude (vôo sub-orbital), por três viagens sucessivas em junho, setembro e outubro de 2004.

No ramo de transportes e posicionamentos de satélites em órbita terrestre, há o "Sea Launch", com capital de empresas dos EUA, Rússia, Ucrânia e Noruega. É um empreendimento para o lançamento comercial de foguetes a partir de uma base oceânica no Pacífico e na base de Baikonur no Cazaquistão (Land Launch).

É importante salientar a participação do Brasil no setor astronáutico, por meio de um conjunto completo de investimentos tecnológicos e em recursos humanos na MECB (Missão Espacial Completa Brasileira), tais como: a AEB (Agência Espacial Brasileira); a participação efêmera no grupo de construção da EEI e o envio do astronauta e cosmonauta Marcos Pontes para aquela estação espacial; a fabricação, a montagem e testes de foguetes, satélites e seus componentes, por várias instituições nacionais, principalmente o CTA (Centro Tecnológico de Aeronáutica), o ITA (Instituto Tecnológico de Aeronáutica) e o INPE (Instituto Nacional de Pesquisas Aeroespaciais), respectivamente e o uso de duas bases de lançamentos de foguetes de pequeno porte (Barreira do Inferno - RN e Alcântara - MA).

O CLA (Centro de Lançamento de Alcântara) possui grande potencial para ampliação de lançamento de cargas maiores, como é o caso da preparação do sítio comercial destinado ao foguete ucraniano Ciclone 4.

A base de Alcântara tem diversas vantagens únicas em sua localização. Ela é a base de lançamentos melhor posicionada no planeta, pois é a mais próxima ao plano do Equador, $2^{\circ}$ de latitude Sul, o que se constitui em uma economia de combustível para os foguetes em até 30\% (COSTA FILHO, 2002). A base situa-se próximo ao litoral, o que é um importante fator de segurança para falhas em lançamentos e está estabelecida longe de grandes cidades, 0 que diminui a possibilidade de loteamentos habitacionais e comerciais das áreas do entorno da base.

Todos estes exemplos demonstram que o Espaço Cósmico ou Exterior também foi apropriado pela Humanidade e que este também deve se tornar parte dos estudos da Geografia.

A atuação da Humanidade no Espaço Cósmico ou Exterior é um assunto que deveria ser explorado no Ensino de Geografia pela Cosmografia. Por outro lado, a ação do Homem no Espaço Exterior também deverá ser estudada, discutida e analisada pela 
Geografia Política, nos próximos anos, pois este assunto envolve o desenvolvimento e a cooperação internacional para o uso de tecnologias da Terceira Revolução Industrial, a produção de lixo espacial e o cumprimento de tratados internacionais no âmbito do Espaço Sideral.

Neste artigo se busca relacionar o Ensino da Astronomia com o Ensino da Geografia em um campo de estudos que faz parte da Cosmografia e será denominado por "Cosmografia Geográfica".

Há um grande cabedal de temas que expressam relações importantes entre os conhecimentos terrestres e os celestes, e que se constitui em uma releitura na área de Geografia, para os quais se propõe a designação de "Cosmografia Geográfica", ao invés do nome "Cosmografia", simplesmente, ou "Geografia Astronômica".

No tocante à superfície terrestre, entende-se que ela é uma continuidade de um espaço muito mais amplo, porém não menos complexo, que é o Espaço Sideral ou Exterior, que é estudado pela Astronomia, pela Astronáutica e em parte pela Cosmografia, no entanto, com metodologias distintas das Ciências Humanas.

\section{A origem do termo "Cosmografia", etimologia e consequências de sua definição simples}

Alguns estudiosos indicam que a palavra "Cosmografia" foi utilizada pela primeira vez no século II d.C. por Claudius Ptolomeu como título de uma obra de cunho geográfico e cartográfico, enquanto há registros (ENCICLOPÉDIA MIRADOR INTERNACIONAL, 1992 e MOURÃO, 1995) de que a palavra "Cosmologia" é anterior, e surgiu no idioma grego como o título de uma obra referente à "Filosofia Física", cujo autor foi o poeta e historiador grego Íon (483-422 a.C.), e ainda, segundo estas fontes, mais tarde a "Cosmologia" ressurgiu no idioma inglês em 1656, em francês em 1754, e em português, espanhol e italiano no século XVIII, portanto, sem data definida para esses três últimos idiomas.

Segundo a GRANDE ENCICLOPÉDIA PORTUGUESA E BRASILEIRA (194-), O filósofo Christian Wolff (1679-1754), autor de uma obra intitulada "Cosmologia Generalis" de 1731, deu o nome de Cosmologia ao estudo das leis gerais do Universo e da sua constituição de conjunto, não só do ponto de vista propriamente científico ou experimental, mas também metafísico.

Quanto à "Cosmografia", ela parece ter ressurgido em Portugal, anteriormente à "Cosmologia", entre 1416 e 1419 no nome da hipotética "Escola de Sagres de Navegação e Cosmografia", supostamente situada na Vila do Infante, cujo nome foi uma homenagem ao fundador da escola, o Infante D. Henrique (1394-1460).

A palavra "Cosmografia" que é utilizada na língua portuguesa foi originada pelo processo fundamental da derivação sufixal, no qual o sufixo "grafia" foi acrescentado à raiz "cosmo".

Há correspondentes desta palavra, com estrutura similar, em outros idiomas ocidentais, tais como o grego [kosmographía], o italiano [cosmografia], o espanhol [cosmografia], o francês [cosmographie], o inglês [cosmography] e em outros.

A origem da palavra é grega:

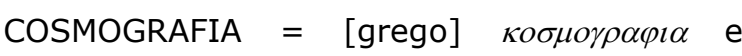
provém da seguinte combinação: 


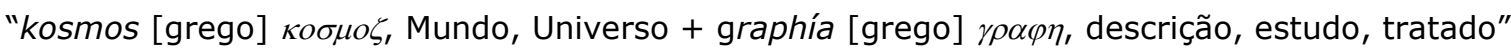

Disto resulta a definição mais rudimentar de Cosmografia, herdada da Antiguidade Clássica, que é a "descrição do Universo".

É fácil compreender porque essa definição prevaleceu desde os tempos da Grécia Antiga até a Renascença prételescópica.

A concepção do Universo era limitada ao sentido da visão humana e constituía-se em um pequeno conjunto de astros, composto de apenas cinco planetas (planam [grego] = errante) visíveis a olho nu (Mercúrio, Vênus, Marte, Júpiter e Saturno), a Lua e o Sol (que do mesmo modo eram considerados "planetas" naquela definição, e modernamente, eles são um satélite natural e uma estrela, respectivamente) e cerca de seis mil estrelas "fixas".

O Universo era aceito pela maioria dos pensadores como sendo 0 todo harmonioso, organizado, imutável, finito e até eterno para alguns, com um pouco mais de um bilhão de quilômetros de raio, como foi estimado na época por Nicolau Copérnico.

$\mathrm{Na}$ atualidade a definição de "cosmo", ou seja, o Universo ou o Mundo, como o todo harmonioso ou organizado, não serve, é incompleta, pois ela é contrária aos estudos mais avançados em Física e em Astronomia sobre o "caos".

O Universo considerado como um todo, sem detalhamentos, sem dúvida, deve ser percebido como organizado e em harmonia, mas quando se trata de pormenores das órbitas dos sistemas planetários e estelares e eventos de dimensões galácticas, o "caos" tem que ser prezado.

A concepção de Universo ou de Mundo, da atualidade, deve abranger todos os fenômenos físicos conhecidos, como por exemplo, o "Big-Bang" e os eventos associados à Astrofísica de Altas Energias. Tais fenômenos não são harmoniosos ou organizados, pois envolvem transformações de elevadas quantidades de energia, tais como nos buracos negros, nas supernovas, nos quasares e nos núcleos ativos de galáxias, em geral, e ainda, os estudos de sistemas dinâmicos caóticos em Mecânica Celeste.

Todos esses fenômenos físicos são apreciados pela Cosmologia Moderna não podendo se constituir em área de estudos da Cosmografia atual; o que Ihe restou, por fim foi a descrição de uma cosmovisão desatualizada do Universo organizado e em harmonia.

Analisando ainda o termo "Cosmografia", verifica-se no exame do significado de "graphía" ( $(\rho \alpha \varphi \eta)$, que esta palavra também poderia ser entendida, para os antigos gregos como, "estudo ou tratado do Universo".

Os sufixos "grafia" (descrição, estudo, tratado) e "logia" (tratado, ciência, discurso) são análogos quanto à tradução para a palavra "tratado". Consequentemente podese afirmar que as traduções simples para "Cosmografia" e para "Cosmologia" são muito próximas, quase as mesmas, o que é absurdo, dada às diferenças fundamentais entre estes dois campos científicos, quanto aos métodos e aos objetos de estudos deles.

\footnotetext{
* Graduado (Licenciatura e Bacharelado) em Geografia (1994),Mestre (2002) e Doutor (2006) em Geografia Física, pela USP. Professor Adjunto da UFG - Planetário de Goiânia e atua na graduação e no Programa de PósGraduação e Pesquisa em Geografia do Instituto de Estudos Socioambientais - UFG. Email: sobreiracosmografia@yahoo.com.br
} 
Como as palavras "Cosmografia" e "Cosmologia" são diferentes na origem e no significado, também se deve atentar para o fato de que o correspondente grego para a palavra "Universo" é igualmente discutível.

Em grego tem-se que: UNIVERSO = [grego] $\pi \varepsilon \rho \iota \phi o \rho \alpha$, portanto, é diferente da palavra $\kappa o \sigma \mu o \zeta$, que a rigor significa "cosmo", boa ordem, organizado, harmonioso, Mundo; então, a Cosmografia é o "estudo ou tratado

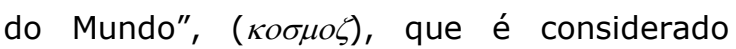
fisicamente como o todo.

O conceito e as expressões das palavras gregas para o Universo são diferentes de Mundo.

Quando o Mundo é entendido concretamente como somente o planeta Terra, então a palavra em grego utilizada

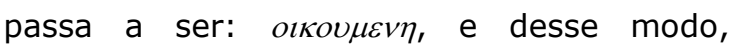
também se pode afirmar que as traduções para "Cosmografia" e para "Geografia" (ge, gaia $=$ [grego] Terra + graphía [grego] descrição, estudo, tratado) são muito próximas, quando se trata do "estudo ou tratado do Mundo", considerado como somente o planeta Terra, o que também é inaceitável, dada às diferenças fundamentais entre elas.

Para enfatizar as semelhanças conceituais entre a Cosmografia e a Astronomia é interessante ainda comparar outro significado atribuído à Cosmografia, que é o "estudo ou o tratado do Universo", com o "estudo ou o tratado do céu", do qual provém o termo "Uranografia" (ouranós = [grego] céu + graphía [grego] descrição, estudo, tratado), que surgiu no idioma inglês em 1675, em francês em 1762, em espanhol entre 1765 e 1783, em italiano entre os séculos XVII e XVIII, e em português no século XIX (ENCICLOPÉDIA MIRADOR INTERNACIONAL e MOURÃO, op. cit.).
Isso demonstra a estreita relação entre a Cosmografia e os estudos de Uranografia ou Astronomia, pois segundo MOURÃO (op. cit.), a Uranografia é equivalente à Astronomia, mais precisamente ao ramo da "Astrometria", ou ainda à "Uranometria", este último foi um termo criado em 1603 pelo astrônomo alemão Johannes Bayer (1572-1625).

Afinal, se a definição de Cosmografia é equivalente a de Uranografia, então ela é, do mesmo modo, praticamente a mesma de Astronomia, apesar de atualmente os objetos de estudos de essas três áreas científicas serem diferentes, o que é absurdo nos dias atuais.

A conclusão parcial a respeito da definição do vocábulo "Cosmografia", até este ponto, é que ela compartilha temas de estudos da Geografia, da Cartografia e principalmente da Astronomia, com a qual ela se confunde.

Os vários conceitos sobre 0 termo "Cosmografia"

O que
fundamentalmente, distingue,
realizadas pela Cosmografia para as de
outros ramos do conhecimento são o
método e os diferentes pontos de vista
empregados nos estudos desses mesmos
temas.

LOURENÇO (2002), ao analisar a obra do Barão Alexander Friedrich von Humboldt, intitulada: "Cosmos. Ensaio de uma descrição física do Mundo ${ }^{1 ",}$, primeiro volume publicado em 1845, mostra que há uma variante na tradução de uma palavra do subtítulo desta obra em alemão: weltbeschreibung, traduzida por "descrição do Mundo", mas que comporta em sua filiação em alemão e em português, a aproximação ao verbo "escrever", do qual

\footnotetext{
1 HUMBOLDT, Alexander von. Kosmos. Entwurf einer physischen weltbeschreibung. 5 Bände. Stuttgart und Tubingen. J. G. Gotta'scher Verlag, $1845,1847,1850,1858,1862$.
} 
deriva "descrever", ou ainda, como em latim "scribere" que é "colocar em letras", e pode ainda ser interpretado como "colocar o Mundo em letras" ou uma "tradução do Mundo", ou como pretendia Humboldt em sua obra, um "ensaio de uma tradução" ou "as múltiplas formas de escrever o Mundo".

Considerando-se a contribuição de Humboldt, se deve cunhar o primeiro conceito para o vocábulo "Cosmografia" como contribuição deste artigo: "É um ensaio da tradução do Mundo e as múltiplas formas de escrevê-lo, sendo o Mundo considerado como o todo universal harmonioso e, portanto, organizado, no qual a Terra está contida e inserida".

Os conceitos de Cosmografia nas obras do século XIX, CHAPUT (s.d.), BERTHELOT (19--) e VIDAL (1901) são ineficientes e inconvenientes para a atualidade, pois confundiam a Cosmografia, quase totalmente, com os estudos astronômicos e generalizavam em demasia o significado dela.

Algumas obras do século $X X$ possuem citações lamentáveis para 0 conceito de Cosmografia, tais como: CURSO DE COSMOGRAPHIA ELEMENTAR (1923), AUGÉ (1929) e FAJARDO (193-):

CURSO DE COSMOGRAPHIA

ELEMENTAR (1923) explicitou o nível de inferioridade científica assumido por aqueles que ensinavam Cosmografia (engenheiros e advogados em sua maioria), no início do século $X X$, pois menosprezou o trabalho dos educadores daquele período ao afirmar:

"(...) limita-se em recolher os resultados dos astrônomos, agrupá-los num resumo cômodo e pô-los ao alcance dos que não têm o tempo de estudar o Universo a fundo; (...) Só os grandes sábios podem realmente dedicar-se à Astronomia; mas qualquer pessoa está habilitada a fazer um pouco de Cosmografia".
(CURSO DE COSMOGRAPHIA ELEMENTAR, 1923, p. 14)

AUGÉ (1929) considerava que a Cosmografia fosse sinônimo de Cosmogonia e Cosmologia, que são áreas ou campos de estudos completamente diferentes entre si.

FAJARDO (193-) fez uma previsão imprudente quanto às futuras determinações das dimensões, formas e das composições da maior parte dos astros, ao afirmar que: "(..) embora para a maior parte desses corpos, as conclusões a que se tem chegado até hoje, sejam puramente conjeturais e não passarão mesmo jamais de simples e frágeis hipóteses".

A previsão para a posteridade (pós década de 30 do século $X X$ ) foi ingênua e a afirmação demonstrou ao mesmo tempo a falta de conhecimento do autor a propósito de métodos astrofísicos para as determinações das dimensões, formas, distâncias, temperaturas e composições dos astros, em geral, aplicados desde o século XIX.

Segundo a maioria dos autores consultados, a Cosmografia seria considerada um estudo meramente descritivo e apresentaria de forma elementar as informações sobre o Universo. A Cosmografia não seria considerada um campo de estudos capaz de obter informações da natureza por meios autônomos, mas ela seria dependente da Astronomia e das Geociências para isso.

Até o século XIX, os objetos de estudos da Cosmografia se equiparavam aos da Astronomia, da Geografia, da Cartografia e da Náutica, sendo até confundida com os conhecimentos científicos delas, pois somente em meados daquele século a Geografia e a Cartografia se tornaram ciências independentes.

Entre o final do século XIX e a primeira metade do século $X X$, a Cosmografia tornou-se uma disciplina escolar que transmitia os conhecimentos mais 
elementares de Astronomia, ora com independência nos currículos escolares, ora como parte dos conteúdos da Geografia.

Como disciplina curricular

independente (extinta no Brasil em 1931, pela

"Reforma Campos"), ela se assemelhava ao conteúdo geométrico da Matemática (Geometria Esférica). Como parte da Geografia, a Cosmografia era um cabedal de conhecimentos descritivos e mnemônicos, que perdeu toda a potencialidade na escola para que os alunos efetuassem relações interdisciplinares.

\section{O conceito de "Mundo"}

Há também uma aparente ambiguidade para o significado da palavra "Mundo", muito usual para o conceito de "Cosmografia", que confunde o Universo e a Terra, e isso se deve à herança da definição de "cosmos" da Grécia pré-aristotélica.

Dessa maneira, há que se considerar que em Astronomia, o Mundo é uma totalidade de campo, ou seja, o Mundo Observável e que atualmente a idéia de ordem não serve mais e que há de se ponderar a existência do caos.

Ao longo do tempo a cosmovisão ou conceito de "Mundo" mudaram, assim como o significado do termo "Cosmografia", em consequência, os objetos de estudos desse campo também. Atualmente, ela não possui o mesmo propósito da Cosmografia dos séculos XIX e XX. Nas últimas décadas do século $X X$ ocorreram grandes avanços nos conhecimentos das ciências celestes e terrestres e que exigiram especializações e subdivisões dessas áreas.

A partir do significado de "Mundo" (para Kant) pode-se considerar que a definição de "Cosmografia", que parece ter dominado o campo das idéias entre os geógrafos dos séculos XIX e XX foi a do conjunto da obra "Cosmos" de Humboldt.

Para esclarecer: o "Mundo" considerado como a Terra é o objeto de estudo da área das Geociências e, em particular da Geografia, enquanto o "Mundo" considerado como o Universo (observável ou não) é o objeto de estudo da Astronomia e, em particular, da Cosmologia. É recomendável como sugestão a partir de este estudo, a distinção entre o Mundo Terrestre e o Mundo Sideral ou Cósmico por estas ciências, respectivamente.

A partir do estudo do conceito de "Mundo" conclui-se que, as diversas definições para Cosmografia dependem das visões do Mundo, em uma época, e das concepções políticas de quem as formulou.

A Cosmografia atualmente não pode ser definida como o estudo (ou descrição ou tratado) do Mundo, pois é necessário decidir sobre qual "Mundo" se está abordando, a Terra ou o Universo (o Terrestre ou o Sideral ou Cósmico), e em qualquer um desses "Mundos" há um campo específico de estudos e que não pode ser objeto exclusivo da Cosmografia.

Assim, o conceito para o vocábulo "Cosmografia", segundo Humboldt se torna: "É um ensaio da tradução e as múltiplas formas de escrever as interfaces entre os estudos do Mundo Sideral e do Mundo Terrestre".

\section{Uma breve cronologia da Cosmografia}

Os estudos cosmográficos resistem na intersecção entre os estudos celestes e os terrestres. A Cosmografia não prosperou desde o século XIX, pois não houve e não há cosmógrafos na atualidade (pesquisadores especialistas em Geografia e igualmente em Astronomia) para levar à frente este debate. 
Nos últimos duzentos anos os cosmógrafos desapareceram, pois segundo a GRANDE ENCICLOPÉDIA PORTUGUESA E BRASILEIRA (194-), o antigo ofício de Cosmógrafo-mor do reino de Portugal foi abolido por um alvará de 5 de agosto de 1779, e as suas atribuições passaram inicialmente para a Academia Real da Marinha, criada então naquele momento, e depois para o presidente do Conselho do Almirantado de Portugal.

A complexidade histórica da Cosmografia e suas mudanças de objetos de estudos ao longo do tempo são pouco conhecidas e pesquisadas, por isso, ela tem perdido importância acadêmica e se tornado uma área do conhecimento renegada a um plano inferior de interesses.

É possível estabelecer em linhas gerais alguns fatos e/ou períodos fundamentais para se discutir brevemente a cronologia da Cosmografia:

- No período entre a Antiguidade e a Idade Média na Europa predominaram diversos modelos de concepções da estrutura do Universo, a forma e a posição cósmica da Terra, inclusive com as primeiras estimativas das dimensões de nosso planeta.

- Entre o final da Idade Média e da Moderna, o destaque foi para a aplicação das técnicas astronômicas na Náutica por cosmógrafos, que atuavam também como cartógrafos, técnicos de instrumentos astronômicos e pilotos. Este foi o auge da Cosmografia em uso nas navegações.

- Na Idade Moderna teve início o Ensino de Cosmografia em escolas jesuítas, porém no final do Renascimento a Cosmografia foi perdendo importância na Náutica.

- O século XVIII foi o período das melhores e mais precisas medidas das dimensões e o estabelecimento da forma da Terra, até aquele momento.

- No século XIX ocorreu a influência da Filosofia Positivista de Auguste Comte, quanto à introdução do Ensino de Astronomia nos manuais didáticos europeus e brasileiros e a publicação por Humboldt da obra "Cosmos", que foi um marco para a estruturação da Geografia Física e também para o Ensino da Cosmografia que, em decorrência disso marcou sua permanência nas escolas brasileiras (Imperial Colégio Pedro II no Rio de Janeiro) como disciplina independente.

- A primeira metade do século XX se caracterizou pela extinção da disciplina de Cosmografia no Brasil e a manutenção dela em conteúdos diluídos nas disciplinas de Geografia, Ciências e Física, até os dias atuais.

- Pós-guerra: a Era Astronáutica e da Ecologia Cósmica e Planetária, que aproximou a Cosmografia da Geografia escolar (Cosmografia Geográfica).

Ao final do século XVII e ao longo do século XVIII, quando se desencadeou a $1^{\text {a }}$ Revolução Industrial, as áreas técnicas exigiram o aperfeiçoamento e a especialização crescente dos profissionais, 
com isso, a importância da Cosmografia, generalista, e da mão-de-obra dos cosmógrafos foi decaindo. Os quatro principais fatores processuais que levaram à decadência da Cosmografia na Idade Moderna foram:

1. Ideológico: os modelos de Sistemas de Mundo não envolviam mais relações diretas entre as estruturas da Terra e do céu, que passaram a ser estudos cada vez mais distintos e especializados, principalmente com o surgimento da Geologia, da Geodésia, da Astronomia Estelar e da Cosmologia;

2. Identidade: a especialização e a valorização da mão-de-obra Náutica, que dispensava os conhecimentos generalistas dos cosmógrafos, que passaram cada vez mais a se afeiçoar aos métodos da Cartografia e da instrumentação astronômica, gerando especializações internas à Náutica e à Cosmografia, que paulatinamente foi perdendo a exclusividade de seus objetos de estudo;

3. Distanciamento da Geografia: A inauguração do Ensino de Geografia (descritiva) na França. Apesar da existência de confusão entre os objetos de estudos da Geografia e da Cartografia, este fato iniciou o afastamento entre a Geografia e a Cosmografia, pois os temas geográficos eram dedicados somente aos estudos topográficos e corográficos da França e de outros poucos países. Isto não significou um rompimento entre a Geografia e a Cosmografia, mas apenas um temporário afastamento entre os conteúdos abordados;

4. Extinção profissional: a abolição do cargo de Cosmógrafo-mór em Portugal, em 1779, que passou suas funções para o presidente do Conselho do Almirantado da Marinha.

O conceito atual do termo "Cosmografia": A Cosmografia Geográfica

A Cosmografia é um saber escolar (Ensino de Astronomia em Geografia). Tal como a Geografia, o conceito de Cosmografia também deve buscar compreender as relações entre o homem e o meio (sideral), ou entre a sociedade e a natureza (aeroespacial), ou da ação do homem na transformação da natureza (cósmica), o que implica também em interfaces com a Ecologia e as Ciências Aeroespaciais (Astronáutica) e suas implicações comerciais e políticas (Geografia Política).

A seguir serão apresentados alguns itens que o conceito de "Cosmografia" deve abranger:

- É composta pela intersecção da Geografia e da Astronomia, mas não exclusivamente por elas, pois se deve ponderar sobre as contribuições da Geodésia, da Cartografia e da Matemática neste estudo;

- Enfoca a Terra como um planeta em suas relações com o Sol e a Lua e determina o lugar dela ou sua posição em relação a eles;

- É um estudo predominantemente escolar sobre os astros observáveis a olho nu e através de quaisquer instrumentos, no qual a Terra está contida e inserida;

- Analisa a interface entre os temas terrestres e os celestes, e suas implicações para a sociedade e a natureza. 
O propósito deste trabalho também é apresentar um subsídio gráfico, para a elaboração de um esquema teórico para a Cosmografia, tal como a Figura 1:

FIGURA 1 - ESQUEMA TEÓRICO DA COSMOGRAFIA

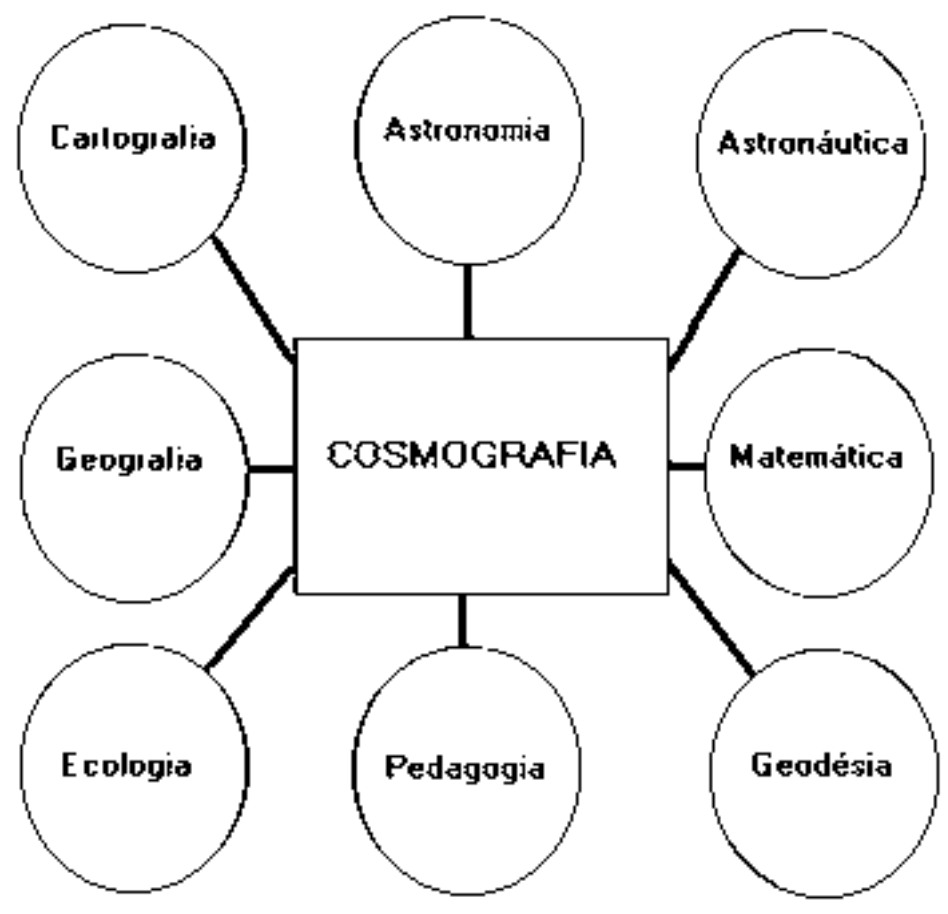

A definição final envolve algumas das considerações anteriores e sugere quais são os objetos de estudos da ressignificação do conceito de "Cosmografia", que será conhecida como "Cosmografia Geográfica":

"A Cosmografia Geográfica é um campo de estudos da Geografia, cujo conjunto de conhecimentos e habilidades é predominantemente escolar. Estuda a interface entre os conhecimentos terrestres e os celestes e Ihes atribui significância geográfica. Analisa as relações humanas e naturais com o Espaço Sideral e suas consequências para a sociedade e a natureza e, portanto, para a organização do espaço."

* Graduado (Licenciatura e Bacharelado) em Geografia (1994),Mestre (2002) e Doutor (2006) em Geografia Física, pela USP. Professor Adjunto da UFG - Planetário de Goiânia e atua na graduação e no Programa de PósGraduação e Pesquisa em Geografia do Instituto de Estudos Socioambientais - UFG. Email: sobreiracosmografia@yahoo.com.br 


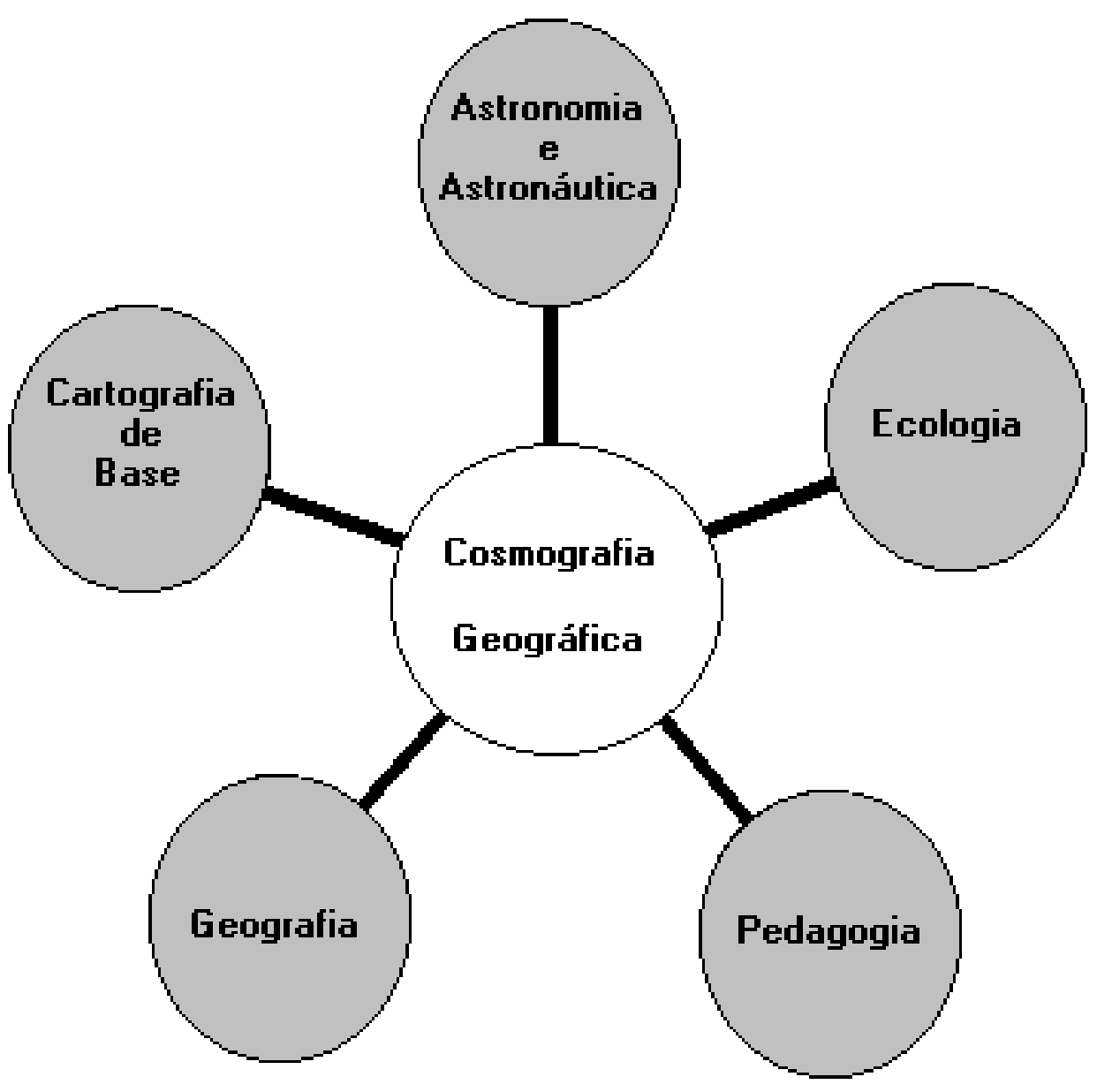

Esse esquema teórico da Cosmografia Geográfica reflete essencialmente a natureza pluridisciplinar da Cosmografia e sua função de inter-relação com as ciências sistemáticas da natureza e do homem, quanto aos temas terrestres e celestes. O que diferencia essencialmente a abordagem dos temas terrestres e celestes efetuados pela Cosmografia Geográfica, para as outras ciências são os pontos de vista e os métodos empregados por elas.

\section{Considerações Finais}

A Cosmografia Geográfica é composta pela intersecção de alguns conhecimentos da Astronomia, da Astronáutica, da Geografia, da Ecologia, da Cartografia de Base e da Pedagogia. É o campo de estudos que se interessa pelas relações entre as estruturas e as feições gerais celestes e terrestres, e suas consequências para a sociedade e a natureza, sem adentrar nos domínios específicos da Astronomia ou da Geografia.

Quanto ao ensino, a Cosmografia Geográfica é a denominação mais apropriada para o Ensino da Astronomia em Geografia, em uso nos estabelecimentos de ensino, nos cursos Fundamental e Médio. 
A continuidade da Cosmografia Geográfica no século XXI dependerá do empenho de estudantes que queiram pautar suas carreiras na graduação e na pós-graduação nos campos de estudos dos ensinos de Geografia e de Astronomia.

Este campo de estudos está aberto e aguarda pesquisadores que queiram se aventurar pelos conhecimentos da Terra e do céu.

\section{REFERÊNCIAS BIBLIOGRÁFICAS}

AUGÉ, Paul (org.). Larrousse du $X X^{e}$ siècle en six volumes, tome deuxiéme. Paris: Librairie Larrousse, 1929

BERTHELOT, Mm. (org.). La Grande Encyclopédie - Inventaire Raisonné des sciences, des lettres et des arts - Tome douzième. Paris: Societe Anonyme de la Grande Encyclopèdie II - Lamirault et $C^{\text {ie }}$ Éditeurs, 19--

CHAPUT, Ignace. Elementos de Cosmographia - curso de mathematicas elementares. Rio de Janeiro/Paris: Garnier, s.d. 228p.

COSTA FILHO, Edmilson Jesus. Política espacial brasileira: a política científica e tecnológica no setor aeroespacial brasileiro. Rio de Janeiro: Revan, 2002. 192p.

CURSO DE COSMOGRAPHIA ELEMENTAR. Por uma reunião de professores Programa do Colégio D. Pedro II e de admissão às Escolas Superiores. Rio de Janeiro, Livraria Paulo de Azevedo \& C., 3.ed., 1923. 166p.

ENCICLOPÉDIA MIRADOR INTERNACIONAL. Encyclopaedia Britannica do Brasil Publicações Ltda, São Paulo: Melhoramentos, 1992

FAJARDO, Rogerio. Curso de Cosmographia v.1 - $1^{a}$ parte - $1^{\circ}$ fascículo: noções fundamentais, concepção geral do Universo, indicações sobre os instrumentos mais usuais e suas aplicações. São Paulo: Ginásio de São Bento, 193-. 62p.
GRANDE ENCICLOPÉDIA PORTUGUESA E BRASILEIRA. Volume 11, Lisboa: Editorial Enciclopédia, 194-

HUMBOLDT, Alexandre de. Cosmos: Essai d'une déscription physique du Monde. 4 volumes. Traduction de M. H. Faye et Louis Charles Galuski, Paris: Gide et J. Baudry, 1848-59

LAMB, Ursula. Cosmographers and pilots of the Spanish Maritime Empire. Collected Studies Series: CS499. Great Yarmouth, Norfolk, Great Britain: Variorum, 1995. 282p.

LOURENÇO, Claudinei. Paisagem no Kosmos de Humboldt: um diálogo entre a abstração e a sensibilidade. Universidade de São Paulo - FFLCH Departamento de Geografia. Tese de doutorado apresentada a FFLCH-USP, São Paulo, 2002. 185p.

MOURÃO, Ronaldo Rogério de Freitas. Dicionário enciclopédico de Astronomia e Astronáutica. Rio de Janeiro: Nova Fronteira, 1995. 961p.

SOBREIRA, Paulo Henrique Azevedo. Cosmografia Geográfica: A Astronomia no Ensino de Geografia. Tese de doutorado apresentada a FFLCH-USP, São Paulo, 2006. 239p.

VIDAL, Adriano Augusto de Pina. Noções de Cosmographia elementar. 2.ed., Lisboa: Academia Real das Sciencias, 1901. 178p. 
